\title{
Performance and Emission Analyses of Acetylene Dual Fuel Engine
}

\author{
Roshan Raman, Naveen Kumar, Ankit Lather, Aditya Panjeta
}

\begin{abstract}
Fossil fuels are exhausting day by day at a very faster rate due to excessive demand for energy. Diesel engines are important prime movers used in different industries. When liquid petroleum fuels are burnt in diesel engines they emit harmful exhaust emissions which pollute the environment and may cause severe chronic diseases. Hence to mitigate over-dependency of crude oil and to protect the environment from harmful emissions, different engine experts and scientists have proposed dual fuel combustion technology to utilize low emissions renewable gaseous fuels without compromising its performance. Most of the work in the literature concentrate on utilizing gaseous fuels such as CNG, LPG, biogas, and hydrogen whereas very little quantum of work has been done to utilize acetylene in the IC engine. The higher flame velocity, high auto-ignition temperature, and high calorific value are the important combustion properties of acetylene which makes it more advantageous in CI engine than the available feedstock. The acetylene can be easily produced from calcium carbonate and water. Hence, the author has considered acetylene as a primary fuel in the present study and diesel as a pilot fuel in the modified $C I$ engine. In this experimental investigation, the author has optimized the flow rate of acetylene by analyzing the performance and emission characteristics of the acetylene fuelled diesel engine at different loads and finally, the obtained results were compared with the neat diesel. The acetylene was inducted at a different gas flow rate of 2 LPM, 3 LPM, and 5 LPM. The results show that when acetylene induction takes place at 2 LPM, the brake thermal efficiency (BTE) increases by $1.4 \%$ at full load during dual fuel mode compared to neat diesel. Brake specific energy consumption (BSEC) increases during acetylene induction whereas carbon monoxide, hydrocarbon, and smoke decrease particularly at medium to high engine loads this may be due to homogenous charge mixture formation, leading to stable combustion. However, there is a slight increase in oxides of nitrogen emissions, which may be due to higher flame speed causing uncontrolled combustion at peak loads relative to baseline diesel.
\end{abstract}

Keywords: Acetylene; Dual Fuel, Performance; BTE; CI Engine; Gaseous Fuel and Emission.

\section{INTRODUCTION}

Fossil fuels are our primary source of energy to our present generation and getting depleted at a faster rate [1-5]. Some of gas), coal and oil. With the usage of fossil fuel like coal and

Revised Version Manuscript Received on 10 September, 2019.

Roshan Raman, Centre for Advanced Studies and Research in Automotive Engineering, Delhi Technological University, New Delhi, India, Department of Mechanical Engineering, The NorthCap University, Sector 23A, Gurugram, Haryana, India Automotive Engineering, Delhi Technological University, New Delhi, India.

Ankit Lather, Department of Mechanical Engineering, The NorthCap University, Sector 23A, Gurugram, Haryana, India. (Email: lather83@gmail.com)

Aditya Panjeta, Department of Mechanical Engineering, The NorthCap University, Sector 23A, Gurugram, India. Research and Development Centre, Speedways Electric, Wisteria Club, Gurugram, Haryana, India. the major fossil fuels which are used by us are CNG(natural

Naveen Kumar, Centre for Advanced Studies and Research in

oil, they produce greenhouse gases and some other pollutants which affect our environment [5-10]. The major used fossil fuel is oil (petrol and diesel) and their usage is increasing daily with the increase of population. As population and technology are increasing gradually and so is pollution and so our natural resources are decreasing. The major safety issue is our health and which is not safe due to the pollution caused by the burning of fuels[10-16]. People are facing some major inhalation problems due to the particulate matter present in the air. Therefore researchers started to think of alternative fuel which can produce low emissions and produce high fuel-efficiency. Over several years researchers come up with different fuels like using biofuels, vegetable oils, using some blends and using two fuels simultaneously. But with the vision of better availability, handling and storage alcohol attracted scientists to work on them. And slowly the usage of petrol and diesel (gaseous fuel) increases as an alternative fuel in internal combustion engines. The fuels which are majorly(gaseous) used nowadays are LPG, CNG. Dual fuel option also emerges as a promising option to use 2 fuels in I.C engine to reduce the effects of pollution and fossil fuels. The dual fuel engine works on two fuels one of them is gas and other is liquid (petrol or diesel). The dual fuel engine works as follows first the air-gas fuel mixture is inducted into the engine cylinder. Then a small amount of diesel (secondary) fuel is introduced so that the during compression stroke the diesel will get ignite due to high rise in temperature in compression, which helps in quick combustion of fuel and helps the piston to move towards the bottom dead center to complete the power stroke. With the help of dual fuel engine emissions were reduced as $\mathrm{NOx}, \mathrm{CO}, \mathrm{HC}$, and other factors. Numerous scientists observed different theories and their results. Acetylene also emerged as alternative gaseous fuel which can be accumulated with diesel in a dual-fuel engine. Its properties were a lot alike hydrogen but it can be handled and stored more easily with respect to hydrogen .it is formed with the reaction of calcium carbide with water. BTE was increased by $2 \%$ in dual fuel mode at CR 20 and 21 compared to neat diesel with reducing In $\mathrm{CO}, \mathrm{HC}$ was observed Kumar 2017 observed a fundamental study on the control of the HCCI combustion and emissions by fuel design concept combined with controllable EGR and concluded that there was decrease in pressure ring and maximum heat release rate T.Lakshmanan and Nagarajan 2011 investigated the port injection of acetylene in diesel engine in dual mode and stated that it is possible to run the diesel engine smoothly using acetylene by varying the flow rates.Sudher 2016 
observed that BTE is nearer to neat diesel as the result of continuous induction of acetylene in the intake. Nox can be reduced by the help of EGR technology as NOx is a major issue regarding emission parameters as observed by Khader 2016 and Sudheesh 2010 observed that BTE was comparable with neat diesel and also a complete reduction in smoke level, no to zero with the help of cooling water flow direction on acetylene fuelled HCCI engine.

\begin{tabular}{|l|l|l|l|}
\hline Properties & Acetylene & $\begin{array}{l}\text { Hydroge } \\
\mathbf{n}\end{array}$ & Diesel \\
\hline Formula & $\mathrm{C}_{2} \mathrm{H}_{2}$ & $\mathrm{H}_{2}$ & $\mathrm{C}_{8}-\mathrm{C}_{20}$ \\
\hline $\begin{array}{l}\text { Density kg/m } \\
\text { (At } 1 \text { atm \& 20 }\end{array}$ & 1.092 & 0.08 & 840 \\
\hline $\begin{array}{l}\text { Auto ignition } \\
\text { temperature ( }\end{array}$ & 305 ) & 572 & 257 \\
\hline $\begin{array}{l}\text { Stoichiometric air fuel } \\
\text { ratio, (kg/kg) }\end{array}$ & 13.2 & 34.3 & 14.5 \\
\hline $\begin{array}{l}\text { Flammability Limits } \\
\text { (Volume \%) }\end{array}$ & $2.5-81$ & $4-74.5$ & $0.6-5.5$ \\
\hline $\begin{array}{l}\text { Flammability Limits } \\
\text { (Equivalent ratio) }\end{array}$ & $0.3-9.6$ & $0.1-6.9$ & \\
\hline $\begin{array}{l}\text { Lower Calorific Value } \\
\text { (kJ/kg) }\end{array}$ & 48,225 & $1,20,000$ & 42,500 \\
\hline $\begin{array}{l}\text { Lower Calorific Value } \\
\text { (kJ/m ) }\end{array}$ & 50,636 & 9600 & 2930 \\
\hline $\begin{array}{l}\text { Max deflagration speed } \\
\text { (m/sec) }\end{array}$ & 1.5 & 3.5 & 0.3 \\
\hline $\begin{array}{l}\text { Ignition energy } \\
\text { (MJ) }\end{array}$ & 0.019 & 0.02 & \\
\hline $\begin{array}{l}\text { Lower Heating value of } \\
\text { Stoichiometric mixture } \\
\text { (kJ/kg) }\end{array}$ & 3396 & 3399 & \\
\hline
\end{tabular}

\section{EXPERIMENTAL SETUP}

During experimentation, a single-cylinder four-stroke air-cooled naturally aspirated direct-injection C.I engine was used which develops a $4.4 \mathrm{~kW}$ at $1500 \mathrm{Rpm}$. The engine was used for the dual operation of Acetylene and diesel. Engine specification of the single Kirloskar engine are here.

\begin{tabular}{|l|l|}
\hline Make and model & Kirloskar, TAF 1 \\
\hline Type & 4 stroke, air-cooled \\
\hline General details & $\begin{array}{l}\text { Four stroke, } \\
\text { compression ignition, } \\
\text { direct injection }\end{array}$ \\
\hline Bore/stroke & $87.5 \mathrm{~mm} / 110 \mathrm{~mm}$ \\
\hline Compression ratio & $17.5: 1$ \\
\hline Rated output & $4.4 \mathrm{~kW}$ at $1500 \mathrm{Rpm}$ \\
\hline Injection timing and injection pressure & $\begin{array}{l}2{ }^{\circ} \mathrm{C} \text { BTDC and } 200 \\
\text { bar }\end{array}$ \\
\hline
\end{tabular}

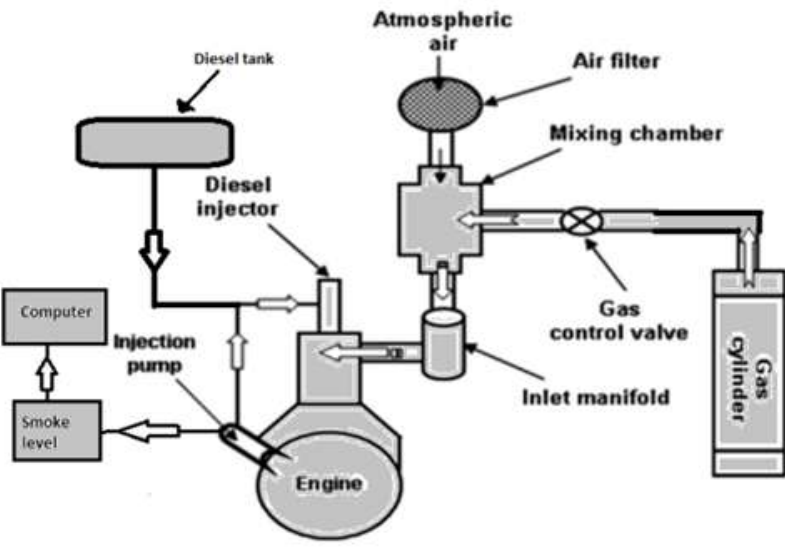

Fig. 1.The block diagram of the experimental setup

\section{RESULT}

\section{- Performance Analysis}

The results which were concluded during performance analyses are BTE and BSFC at different loading conditions and under different flow rates of acetylene i.e. $2 \mathrm{lpm}, 3 \mathrm{lpm}$, and $5 \mathrm{lpm}$.

\section{- Brake Thermal Efficiency}

Fig. 2 shows the variation of BT E with the change in load. The results of dual fuel are slightly lower than the neat diesel fuel working at all loading condition. As the acetylene gas flow rate is increased the brake thermal efficiency for dual fuel starts decreasing. At a partial load of $50 \%(2.3 \mathrm{~kW})$ the BTE for diesel fuel obtained for engine comes out $27 \%$. For dual fuel $21 \mathrm{pm}$ and $31 \mathrm{pm}$ acetylene flow rate the results are almost similar and come out nearly $25 \%$ whereas for $51 \mathrm{pm}$ the results deviate from neat diesel and BTE comes out $22 \%$ which is $5 \%$ less than baseline diesel. At $100 \%$ load $(4.6 \mathrm{~kW})$ the BTE for diesel fuel obtained for engine comes out $30 \%$. For dual fuel operation at $31 \mathrm{pm}$ flow rate of acetylene, the results are improved than neat diesel fuel and an increase of $3 \%$ in BTE is observed. For 2 LPM BTE comes out $28 \%$ and for 5 LPM the BTE is $26 \%$ which is $2 \%$ and $4 \%$ lesser than that of normal diesel

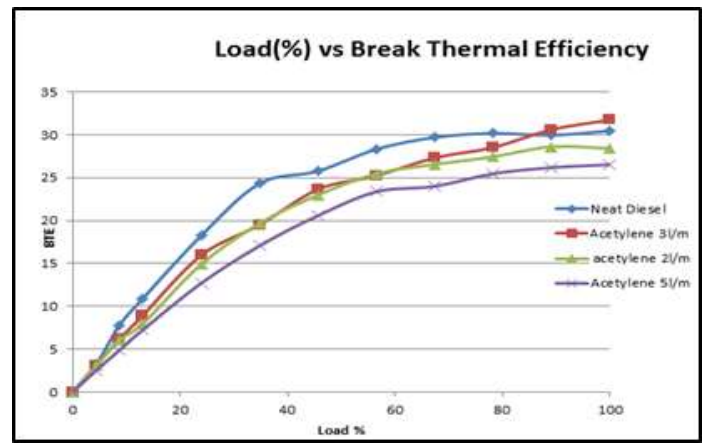

Fig.2 Variation of BTE versus Load

\section{- Brake Specific Fuel Consumption}

Fig. 3 depicts the variation of BSFC with the change in load. The trend observed in the curve drawn between load and BSFC shows that the BSFC at partial load is more and as 
load increase, the BSFC decreases sharply and shows slightly straight-line behavior after $50 \%$ load. The fuel supply at low load is slightly greater in case of dual fuel but as load increases, the BSFC becomes equal to diesel which shows that at higher load both diesel fuel and dual fuel consumption is almost same to give unit break power.

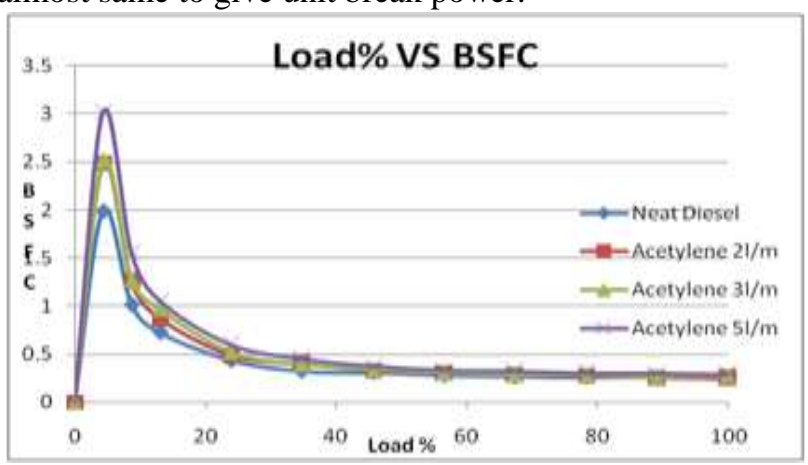

Fig. 3 Variation of BSFC versus Load

\section{EMISSION ANALYSIS \& RESULTS}

The emission analysis was done with the help of gas analyzer. Some of the important emissions are explained below.

\section{- Carbon Monoxide}

Fig. 4 depicts the variation of $\mathrm{CO}$ emissions with the change in load. The minimum $\mathrm{CO} \%$ produced at $2 \mathrm{lpm}$ is $0.02 \%$, at $3 \mathrm{lpm}$ is $0.01 \%$ at $5 \mathrm{lpm}$ is $0.007 \%$ whereas for neat diesel it is $0.02 \%$. The maximum $\mathrm{CO}$ produced at $2 \mathrm{lpm}$ is $0.097 \%$, at $3 \mathrm{lpm}$ is $0.091 \%$, at $5 \mathrm{lpm}$ it is $0.087 \%$ and for neat diesel, it is $0.1 \%$. It may have happened that some of the $\mathrm{CO}$ molecules get converted into $\mathrm{CO} 2$ by converting the additional oxygen atom present in acetylene fuel-air mixture. That eventually reduces the $\mathrm{CO}$ emissions while utilizing acetylene in DFE.

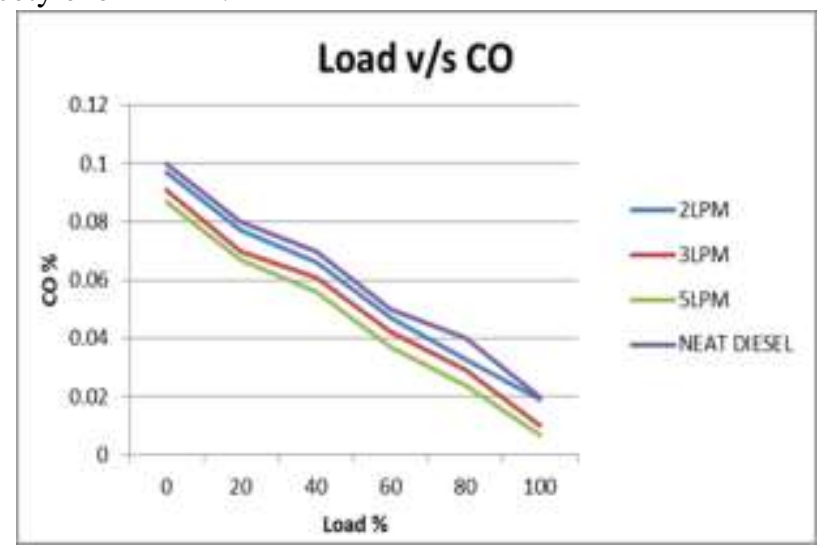

Fig. 4 Variation of CO versus Load

\section{- Oxides of Nitrogen}

Fig. 5 shows the variation of NOx emissions with the change in load. The NOx tends to increase in a linear manner for all the fuels tested, this might be due to the fact that NOx emission increases with the rise in engine temperature and with increasing load, excess fuel is injected which increases the temperature and eventually increases the NOx emissions. Induction of acetylene will lead to a rise in NOx due to the rising peak cycle temperature level. The minimum NOx produced in Parts Per Million (PPM) for 2 lpm, 3 lpm, and 5 lpm were observed 495, 544 and 668 respectively whereas for neat diesel it was approximately 420 at lower loads. For higher load NOx increases substantially i.e. for $2 \mathrm{lpm}, 3 \mathrm{lpm}$ and $5 \mathrm{lpm}$ observed NOx were 2280, 2508 and 3078 respectively. Similarly, for neat diesel, the NOx increases to 1840 ppm at peak loads. Overall, it can be concluded that by increasing load NOx increases for all the cases this might be due to high combustion temperature attained at higher load.

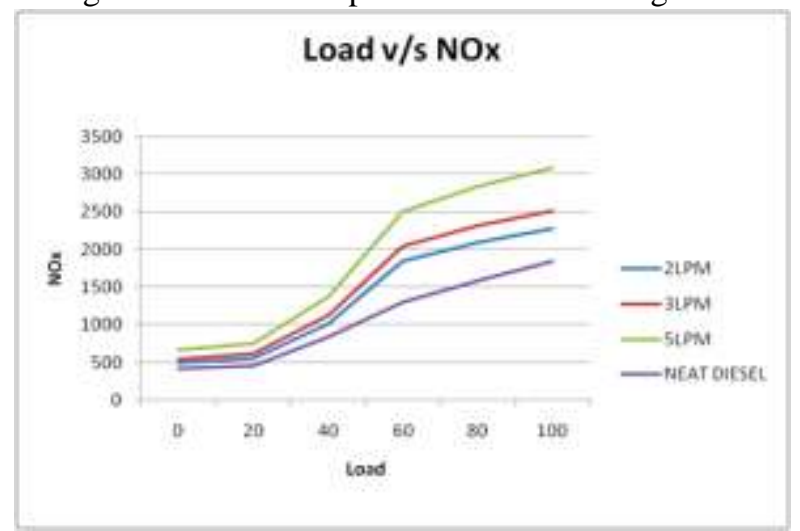

Fig. 5 Variation of NOx versus Load

\section{- Hydrocarbon}

The $\mathrm{HC}$ values were taken in ppm for Kirloskar diesel engine with respect to load for every sample of the fuel tested. Fig. 6 show the variation of HC emissions with the change in load. The HC emissions were increased gradually there was an increase in load conditions for every sample of the fuel tested. HC ranges from $42 \mathrm{ppm}$ to $78 \mathrm{ppm}$ for $2 \mathrm{lpm}$, $39 \mathrm{ppm}$ to $73 \mathrm{ppm}$ for $3 \mathrm{lpm}, 33 \mathrm{ppm}$ to $70 \mathrm{ppm}$ for $5 \mathrm{lpm}$ whereas for baseline diesel $\mathrm{HC}$ rises from $48 \mathrm{ppm}$ to $82 \mathrm{ppm}$ from no load to full load. Overall it can be concluded that HC decreases for acetylene fuelled CI engine compared to neat diesel, this may due to improved combustion.

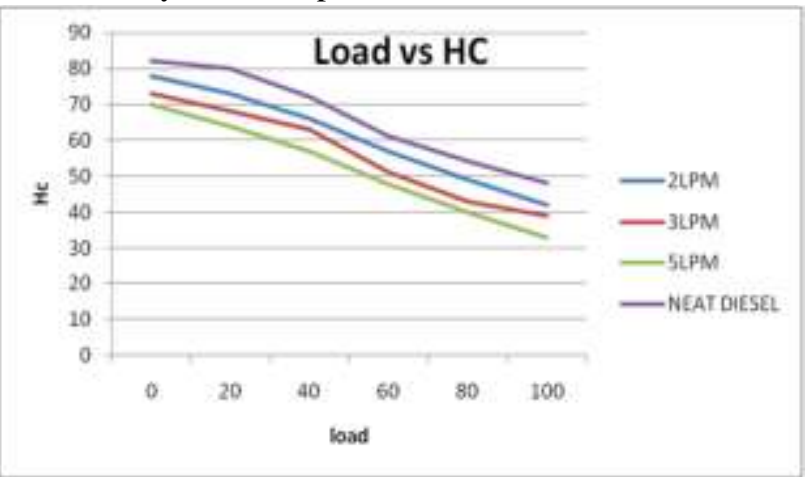

Fig. 6 Variation of HC versus Load

\section{CONCLUSION}

- BTE in a dual-fuel engine is lower in case of full load, resulting in continuous initiation of acetylene in the intake.

- BSFC of dual fuel and diesel fuel is almost the same at full load

- Devaluation in $\mathrm{HC}, \mathrm{CO}$ emissions resulted in an acetylene-diesel aspirated engine.

- Significant increase in the NOx emission is observed in the exhaust. 


\section{REFERENCES}

1. Swami Nathan S, Mallikarjuna JM, Ramesh A. The effect of mixture preparation in a diesel HCCI using early in-cylinder injection during the suction stroke. Int $\mathbf{J}$ Automot.Technol 2007; 8:543-53.

2. Lakshmanan T, Nagarajan G. Experimental investigation of acetylene in DI diesel engine in dual fuel mode, Fuel Processing Technology 2010;91:496-503.

3. Lakshmanan T, Nagarajan G. Performance and Emission of Acetylene-Aspirated Diesel Engine. JJMIE 2009 3(2):125-130.

4. Lakshmanan T, Nagarajan G. Experimental investigation of timed manifold injection of acetylene indirect injection diesel engine in dual fuel mode. Energy 2010a; 35:31723178.

5. Lakshmanan T, Nagarajan G. Experimental investigation of port injection of acetylene in diesel engine in dual fuel mode. Fuel 2011a;90:2571-2577..

6. Behera P, Murugan S, Nagarajan G. Dual fuel operation of used transformer oil with acetylene in a di diesel engine. Energy Conversion Mgmt. 2014;87:840-847.

7. Vijayabalan P, Nagarajan G. Performance, Emission and Combustion of LPG Diesel Dual Fuel Engine using Glow Plug. JJMIE 2009;105-110.

8. K Sudheesh, Mallikarjuna J. Development of an Exhaust Gas Recirculation Strategy for Acetylene Fuelled HCCI Engine.IMechE: Part D-Journal of Automobile Engineering 2010a; 224 (7): 941-952.

9. Swami Nathan S, Mallikarjuna JM, Ramesh A. Effects of charge temperature and exhaust gas recirculation on combustion and emission characteristics of acetylene fuelled HCCI engine.Fuel 2010 89(2):515-521.

10. Mahla S K, Kumar S, Shergill H. Study the Performance Characteristics of Acetylene Gas in Dual Fuel Engine with Diethyl Ether Blends. International Journal on Emerging Technologies 2012;3(1):80-83.

11. Kumar Prabhu, Swaminathan S, Nagalingam B, Gopala KV. Water induction Studies in a Hydrogen Diesel dual fuel engine, Int. Journal of Hydrogen Energy 1987;12:177-186.

12. Sonar D, Soni SL, Sharma D, Srivastava A, Goyal R. Effect of compression ratio on performance, emission and combustion characteristics of diesel-acetylene fuelled single cylinder stationary CI engine Clean Technol Environ Policy 2017;1499-1511.

13. N. Swami, Mallikarjuna, Ramesh. HCCI engine operation with acetylene the fuel. SAE paper no 2008-28- 0032.

14. Sharma PK, Kuinkel H, Shrestha P, Poudel S. Use of Acetylene as an Alternative Fuel in IC Engine. Mech Confab 2012.

15. Schobert H. Production of acetylene and acetylene-based chemicals from coal. Chem Rev 2014 doi:10.1021/cr400276u.

16. Mahla SK, Kumar S, Shergill H, Kumar A. Study The Performance Characteristics Of Acetylene Gas In Dual Fuel Engine With Diethyl Ether Blends 2012;3:80. 